\title{
KrF excimer laser ablation in helium yields the highest amount of SWCNTs over other inert gases
}

\author{
Calin Moise, Adrian Katona, Doru Dinescu, Jasim Al-zanganawee, \\ Dionezie Bojin, Marius Enachescu \\ Center for Surface Science and Nanotechnology, \\ Politehnica University of Bucharest, 060042, Romania \\ cmoise@xnet.ro
}

\begin{abstract}
The single-wall carbon nanotubes (SWCNTs) were synthesized using the equipment, method and experimental conditions described in [1]. Starting from the results shown in [2] and [3] we studied the influence of inert carrier gas over ablated mass, collected material, conducting character of SWCNTs and diameter distribution of SWCNTs. In our study KrF 248nm excimer laser was used instead of Nd:YAG (532nm) in [2] and four ablation gases: argon, nitrogen, neon and helium were involved. This kind of study, performed in our experimental conditions, was not reported so far. The ablated products were characterized using Raman spectroscopy and thermogravimetric analysis. We observed linear decrease of ablated mass with the increase of carrier gas molecular mass. Also the collected mass follows the same trend. TGA allowed us to calculate the mass of SWCNTs contained in the soot and the highest value was obtained in helium, 10 times more than in argon. Also, it was found the thermal conductivity of the carrier gas has a strong influence upon ablated mass and product deposition. The RBM and G Raman bands analysis have shown no influence of carries gas over the SWCNTs diameters distribution, respectively semiconducting character of SWCNTs, in all cases semiconducting SWCNTs being obtained. Our work concludes that helium is the best ablation gas, being 2 times more expensive than nitrogen but producing 8 times more SWCNTs.
\end{abstract}

\section{Introduction}

Since their discovery in the early 1990 s carbon based nanomaterials, especially single wall carbon nanotubes (SWCNTs) are still captivating the interests of plenty scientific groups and industries all over the world, due to their physical and chemical properties. Among the most important applications of SWCNTs we highlight the fabrication of biosensors [4.5,6], scanning microscope tips [7], third generation solar cells [8] and nano-electronics [9], as well as they being good candidate for hydrogen storage.

\section{Experimental}

The laser ablation experiments was carried out in a custom-designed installation depicted in Fig. 1. [1,10, 11]

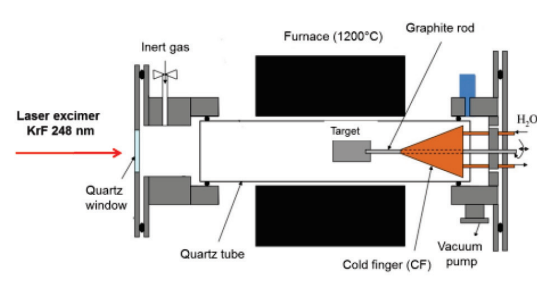

Fig 1. Ablation chamber design

The laser beam coming from the left side of the installation passes through a quartz window entering into a quartz tube and hits the target producing ablation material. Then the inert gas which enters from the left-up side of the installation travels through the $1260 \mathrm{~mm}$ long quartz tube and $60 \mathrm{~mm}$ diameter, caring the ablation product to the cold finger where it will be deposited.In this study we varied the 
ablation gas types while the other parameters: laser type, laser energy, pulse repetition rate, oven temperature, gas pressure, gas flow rate, and ablation time remained constant (Table 1). The laser ablation experiments were carried out in four different inert gases: argon, nitrogen, neon and helium.

\begin{tabular}{ll} 
Parameter & Value \\
\hline Laser type & $\begin{array}{l}\text { Excimer } \mathrm{KrF}, \quad 248 \\
\mathrm{~nm}\end{array}$ \\
$\begin{array}{l}\text { Laser energy } \\
\text { Repetition rate }\end{array}$ & $600 \mathrm{~mJ}$ \\
Pulse period & $20 \mathrm{~Hz}$ \\
Oven & $1100^{\circ} \mathrm{C}$ \\
temperature & \\
Gas pressure & $500 \mathrm{Torr}$ \\
Ablation time & 60 minutes
\end{tabular}

Laser ablation parameters

We used targets prepared in our laboratory using an own developed method which does not require pressing or hot pressing nor sintering $[2,12]$. The target was prepared by mixing a graphite cement (GC 8010-B from Metal Forming Lubricants) with metal micro sized powder of $\mathrm{Ni}$ and $\mathrm{Co}$ (Sigma Aldrich), in the following atomic ratio $\mathrm{C}: \mathrm{Ni}: \mathrm{Co}=98.8: 0.6: 0.6$. The resulting paste was transferred into a Teflon mold $(20 \mathrm{~mm}$ diameter), treated at $130^{\circ} \mathrm{C}$ for 4 hours to improve the mechanical strength. It was followed by a $800^{\circ} \mathrm{C}$ heat treatment in inert atmosphere for one hour to remove all the organic compounds. Finally the target contains only carbon, nickel and cobalt atoms. The target was rotated during ablation with constant speed to get uniform ablation. The cold finger was cooled by a chiller, setup at $12^{\circ} \mathrm{C}$. The collected products were investigated using confocal micro-Raman spectroscopy, thermogravimetric analysis (TGA) and SEM.

\section{Results}

We observed a linear decrease of the ablated mass with the increase of carrier gas molecular mass. Also the collected mass follows the same trend (Fig.2).

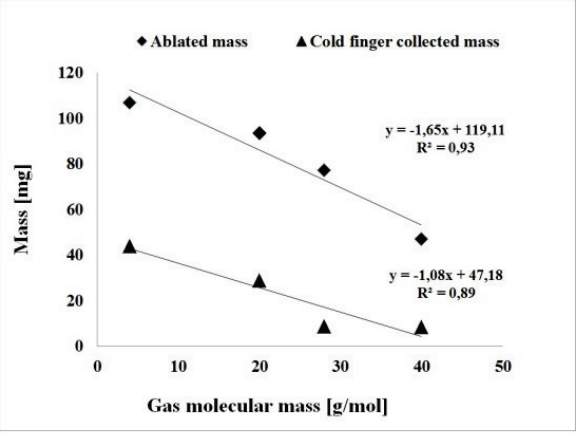

Fig 2. Ablated and collected mass dependence with the ablation gas molecular mass

Also, we found the thermal conductivity of the carrier gas has a strong influence upon ablated mass and product deposition (Fig.3)

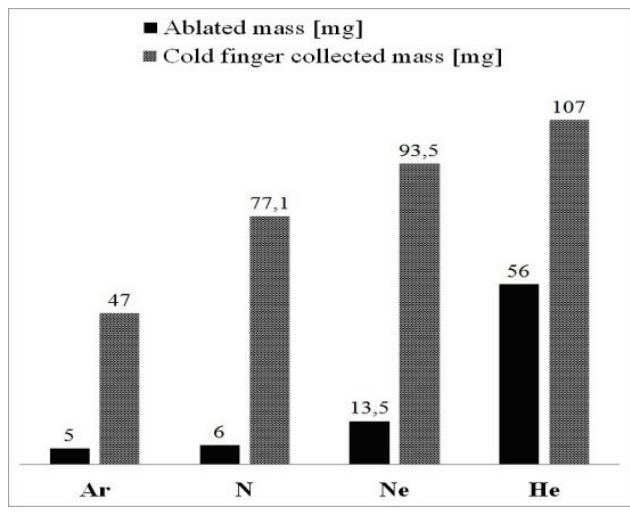

Fig. 3 Collected mass dependence with the thermal conductivity of the ablation gas

The presence of the SWCNTs was revealed by confocal micro-Raman spectroscopy analysis using a $532 \mathrm{~nm}$ green laser (Fig.4). In the radial breathing mode (RBM) zone we found two peaks whose frequencies are strongly SWCNTs diameter dependent. The diameters of the tubes were calculated in accordance with the following equation:

$\mathbf{d}=\mathbf{c 1} /(\omega-\mathbf{c} 2)$

$\omega$ - frequency for vibrations in the radial direction $\left[\mathrm{cm}^{-1}\right]$ $\mathrm{c} 1, \mathrm{c} 2$ - constants $\left[\mathrm{cm}^{-1}\right]$; $\mathrm{c} 1=215\left[\mathrm{~cm}^{-1}\right]$ 
$\mathrm{c} 2=18\left[\mathrm{~cm}^{-1}\right]$

$\mathrm{d}$-diameter of the nanotube [nm]

Two diameters distribution were found 1.31 $\mathrm{nm}$ respectively, $1.47 \mathrm{~nm}$, and proved to be independent over the ablation gas.

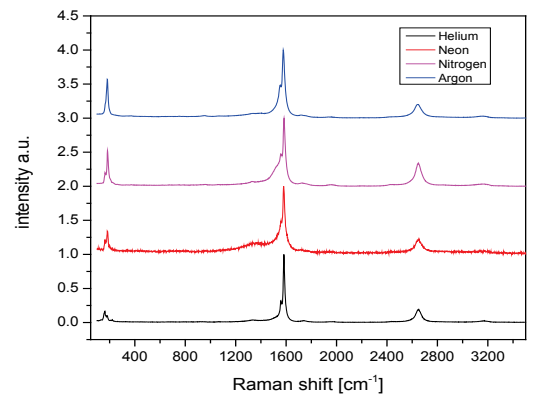

Fig.4 Raman shift dependence with different ablation gases

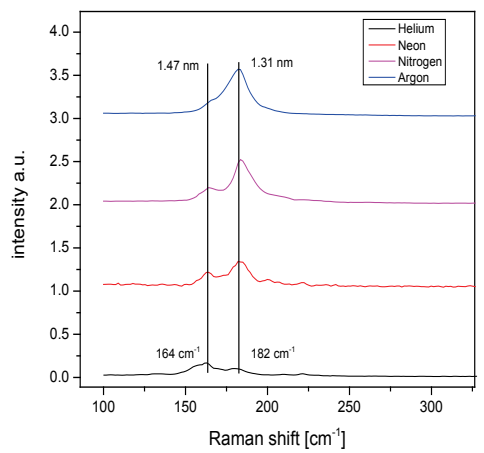

Fig.5 RBM Raman shift dependence with different ablation gases

The $\mathrm{G}$ band in the Raman spectra clearly demonstrates a high ratio of $\mathrm{I}_{\mathrm{G}^{+}} / \mathrm{I}_{\mathrm{G}-}$ proving that in all four inert atmospheres semiconducting SWCNTs were obtained (Fig.6).

TGA analysis performed in air showed that the ablation products contain very little amount of amorphous carbon for all gases (Fig.7), also the products obtained in argon and nitrogen present fractions of fullerenes which burn between $500-600^{\circ} \mathrm{C}$, while those obtained in helium and neon look very clean (Fig.7 and 8). We estimated the percentage of SWCNTs for each ablation gas in part as in Fig.8 then using these results we calculated the effective mass of SWCNTs in the raw ablation product (Table.2)

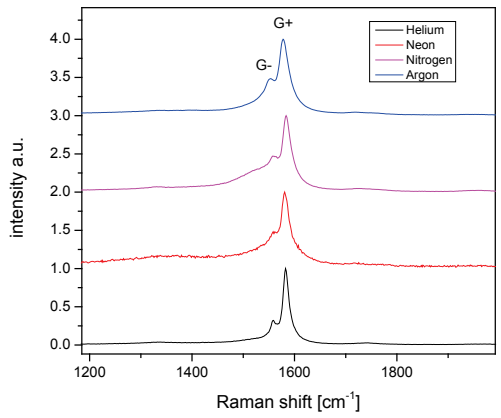

Fig.6 G band Raman shift dependence with different ablation gases

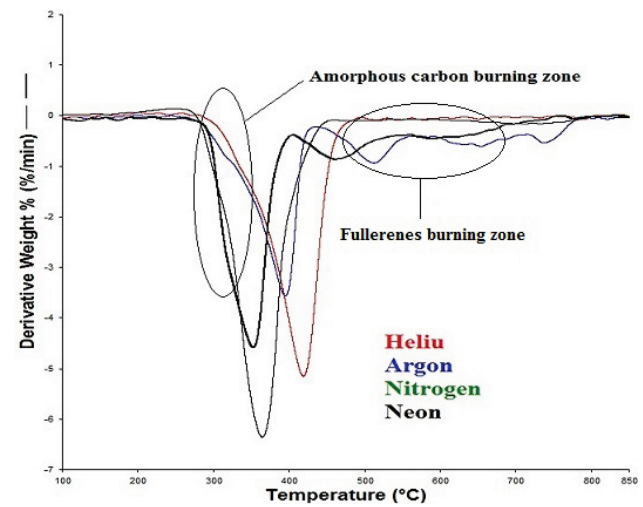

Fig.7 First derivative TGA curves of the ablation product obtained in different inert gases (Gas: air, $\mathrm{T}=100-850^{\circ} \mathrm{C}$ )

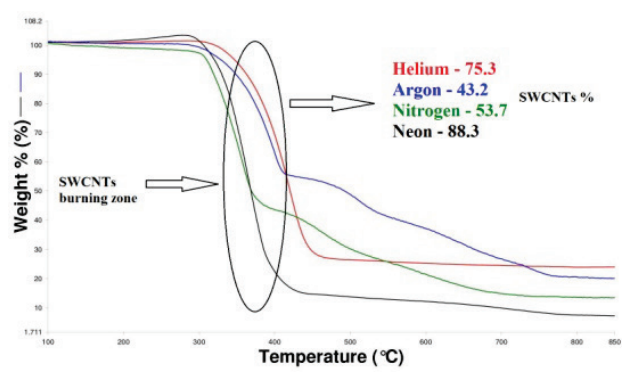

Fig.8 TGA curves of the ablation product obtained in different inert gases (Gas: air, $\mathrm{T}=$ $\left.100-850^{\circ} \mathrm{C}\right)$ 


\begin{tabular}{llll} 
No. & 1 & 2 & 3 \\
\hline $\mathrm{He}$ & 75.3 & 44 & 33.1 \\
$\mathrm{Ne}$ & 88.3 & 28.7 & 25.3 \\
$\mathrm{~N}_{2}$ & 53.7 & 8.6 & 4.6 \\
$\mathrm{Ar}$ & 43.2 & 8.4 & 3.6
\end{tabular}

Table.2 SWCNTs mass calculated from the TGA curves: $1: \%$ of SWCNT in the deposition from TGA curves; 2 : Mass of cold finger deposition [mg]; 3: Mass of SWCNTs produced [mg]

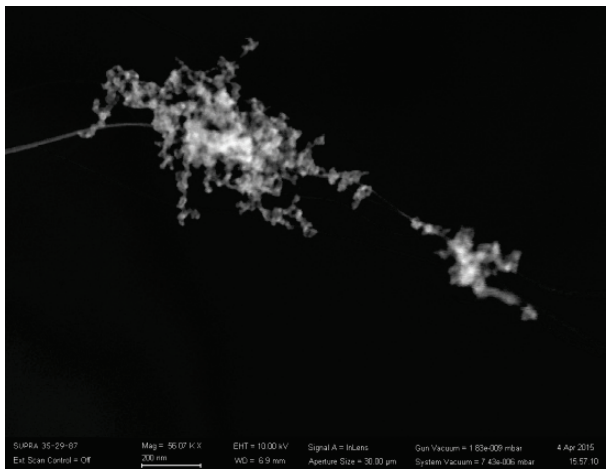

Fig.9 SEM image of SWCNTs obtained in Helium gas

Helium gas led to the highest amount of SWCNTs (Table. 2) with good quality (Fig.4) and micrometers long SWCNTs provided by the SEM image (Fig.9)

\section{Conclusion}

TGA allowed us to calculate the mass of SWCNTs contained in the soot and the highest value was obtained in helium, 10 times more than in argon. Also, it was found the thermal conductivity of the carrier gas has a strong influence upon ablated mass and product deposition. The RBM and $G$ Raman bands analysis have shown no influence of carries gas over the SWCNTs diameters distribution, respectively semiconducting character of SWCNTs, in all cases semiconducting SWCNTs being obtained.
Our work concludes that helium is the best ablation gas, being 2 times more expensive than nitrogen but producing 8 times more SWCNTs.

\section{Acknowledgments:}

This work was supported by Romanian Ministry of Education and by Executive Agency for Higher Education, Research, Development and Innovation Funding, under projects PCCA 2-nr. 166/2012 and ENIAC 03/2013

\section{References:}

1) Bota, M. et al., Surface Engineering and Applied Electrochemistry, 50 (2014), No.4, 294

2) Nishide, D. et al, Chemical Physics Letters, 372, (2003), Issues 1-2, 45

3) Gorbunov, A. et al., Appl. Phys., A 69 [Suppl.], (1999), S593

4) Besteman, K. O Lee, J. Wiertz, F. Heering, H. Dekker, C., Nano Letters, 3 (2003) 727

5) Balasubramanian, K Burghard, M., Anal.Bioanal.Chem., 385 (2006) 452

6) Jain, S. et al., J.Biosens.Bioelectron., S11 (2012)

7) Choi, N., Jpn.J.Appl.Phys., 39 (2000) 3707

8) Dorobantu, D. et al., Proceedings of the $37^{\text {th }}$ Annual Congress of the American Romanian Academy of Arts and Sciences (ARA), June 04-09, (2013) 551

9) Star, A., Gabriel, J., Bradley, K., Grüner, G., Nano Letters, 3 (2003) 459

10) Bota, M., Dorobantu, D., Boerasu, I., Bojin, D., and Enachescu, M., Materials Research Innovations, 19 (2015), No.1, 33 11) Dorobantu, D., Bota, M., Boerasu, I., Bojin, D., Enachescu, M., Surface Engineering and Applied Electrochemistry, 50 (2014), No.5, 390

12) Bota, M., Badea, M., Dorobantu, D., Boerasu, I., Bojin, D., Enachescu, M. sent for publication to International Journal of Heat and Mass Transfer 